Archive for

Organic Chemistry
Arkivoc 2018, part v, 0-0

to be inserted by editorial office

\title{
The synthesis of new functionalized 1,3,5-triazine-based stable bi- and trinitroxides of the 2,5-dihydroimidazole series
}

\author{
Elena V. Zaytseva, ${ }^{* a, b}$ Yury V. Gatilov, ${ }^{a, b}$ and Dmitrii G. Mazhukin ${ }^{a, b}$ \\ a N.N. Vorozhtsov Novosibirsk Institute of Organic Chemistry, Siberian Branch of Russian Academy of Sciences, \\ 9 Acad. Lavrent'eva Ave., Novosibirsk 630090, Russia \\ ${ }^{b}$ Novosibirsk State University, 2 Pirogova Str., Novosibirsk 630090, Russia \\ Email: elena@nioch.nsc.ru
}

Received 05-04-2018

Accepted 07-16-2018

Published on line $08-04-2018$

\section{Abstract}

New non-conjugated functionalized 2,5-dihydroimidazole-type bi- and trinitroxyl radicals are described. The synthesis of which was based on a nucleophilic substitution reaction between 2,4,6-trichloro-1,3,5-triazine or 2,4-dichloro-6-methoxy-1,3,5-triazine and spiro-fused 2,5-dihydroimidazole-type monoradicals bearing both a p-hydroxyaryl moiety at the C-4 atom of the heterocycle and a residue at the fourth position of the cyclohexane ring. The model tris-nitroxide with an unsubstituted cyclohexane unit was structurally characterized in the solid state.

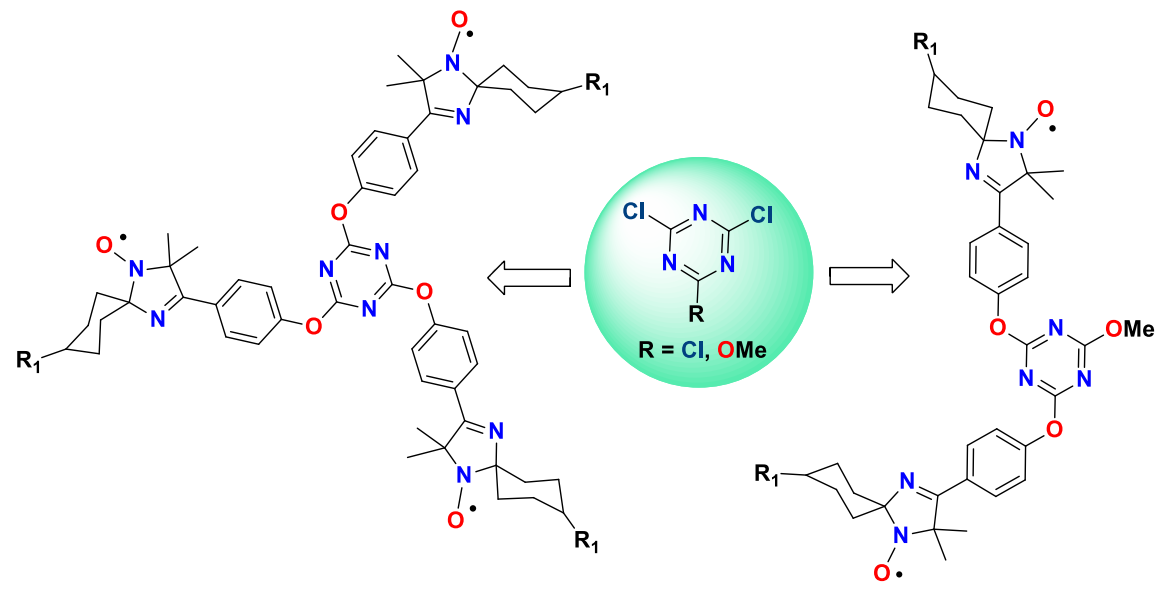

Keywords: 1,3,5-Triazine-based nitroxides, biradicals, triradicals, organic free radicals, 2,5-dihydroimidazoles 
Trisubstituted 1,3,5-triazines represent a rapidly developing class of organic compounds. Due to their symmetrical structure and self-organized ability to form ordered media as well as good thermal stability, $s$ triazines are useful in materials science and manifest a wide range of practical characteristics such as nonlinear optical ${ }^{1,2}$ and liquid crystalline ${ }^{3-8}$ properties including photoluminescence. ${ }^{9}$ In addition, triazine derivatives were recently proved to be stable molecular glasses highly resistant to crystallization, ${ }^{10}$ promising inhibitors of organic corrosion of steel in acids, ${ }^{11}$ and unique scaffolds in the synthesis of highly efficient covalent organic frameworks (COFs) applied to photocatalytic hydrogen production. ${ }^{12}$

Magnetic liquid crystals (LCs) attract a great deal of attention because they may engage in unique magnetic interactions and have unconventional magneto-electric and magneto-optical properties. ${ }^{13}$ Over the last decade, stable organic radicals such as pyrrolidine-type nitroxides (PROXYLs), ${ }^{14,15}$ trityls, ${ }^{16}$ verdazyls, and benzo[e][1,2,4]triazinyls (Blatter's radicals) ${ }^{17-20}$ were used to designing all-organic paramagnetic calamitic, discotic, and bent-core LCs. Unique magnetic, optical, and electronic phenomena have been discovered during research into these types of LCs, e.g., i) unusual anisotropic and inhomogeneous ferromagnetic interactions arising in smectic and nematic LC phases of PROXYL-type rod-like mono- ${ }^{21,22}$ and biradicals ${ }^{15}$ as well as in the hexagonal columnar LC phase of an achiral $\pi$-delocalized hexa-peri-hexabenzocoronene derivative carrying a conjugated tert-butyl nitroxide moiety ${ }^{23}$ induced in a weak magnetic field (the positive magneto-LC effect); ii) existence of two magnetic bistable states in the ferroelectric LC phase of a chiral rod-like PROXYL radical in an applied electric field (magneto-electric effect) ${ }^{24}$; and iii) charge photogeneration and photoinduced ambipolar charge transport in discotic and bent-core conjugated verdazyls and benzo[ $e][1,2,4]$ triazinyls. ${ }^{17-20}$

In this regard, the synthesis of new paramagnetic all-organic liquid crystalline bi- and triradicals containing nitroxide moieties inside the lateral heterocyclic 2,5-dihydroimidazole skeleton as spin sources and a central 1,3,5-triazine core as a robust linker seems to be promising. Besides, an s-triazine core may be a useful template for elaborating synthetic approaches to various disjoint hetero- di- and triradicals containing paramagnetic nuclei of different structural types.

It is worth noting that only a limited number of paramagnetic derivatives - mainly nitroxides, nitronyl nitroxides, and phenoxyls linked with a triazine central core-have been successfully prepared. Three strategies have been implemented to introduce various radical fragments into the $2^{\text {nd }}, 4^{\text {th }}$, and $6^{\text {th }}$ positions of the heterocyclic nucleus: a) nucleophilic substitution of 1-3 chlorine atoms in cyanuric chloride with alkoxy, phenoxy, or amino groups in a reaction with the corresponding paramagnetic alcohols, ${ }^{25-28}$ phenols, ${ }^{29,30}$ or amines $^{31}$; b) organometallic reactions of a radical-protected derivative of arylboronic acid or an organolithium derivative with 2,4,6-trichlorotriazine ${ }^{32}$; c) initial formation of the 1,3,5-triazine nucleus by the trimerization reaction of a functionalized benzonitrile followed by transformation of the functional group into a stable radical. ${ }^{33}$

The present report continues our research on the synthesis of functional derivatives of spirocyclic mono-

and oligoradicals of the azole series. ${ }^{34-36}$ The present paper describes the synthesis as well as structural characterization of new paramagnetic derivatives of 2,4,6-tris(aryloxy)-1,3,5-triazine (1a-c) and of 2,4bis(aryloxy)-6-methoxy-1,3,5-triazine (2a-c; Figure 1). 

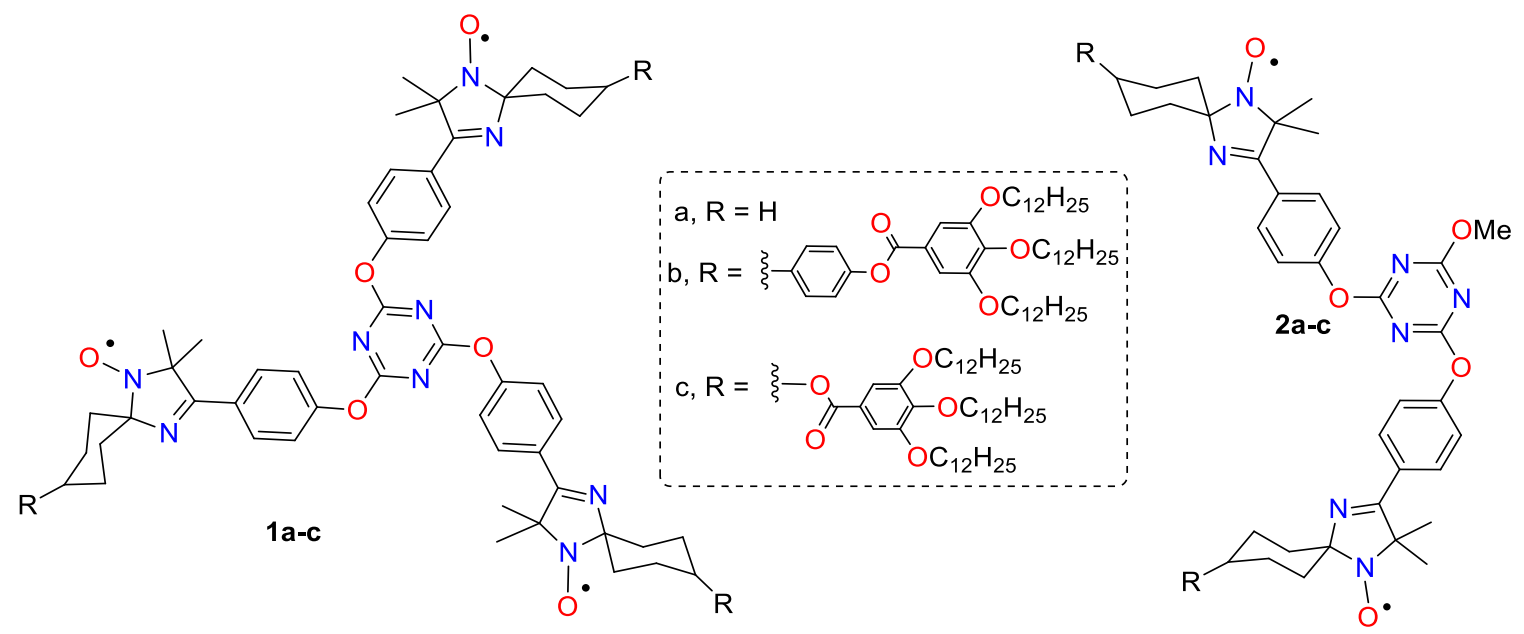

Figure 1. Chemical structures of the desired paramagnetic derivatives of 2,4,6-tris(aryloxy)-1,3,5-triazine (1ac) and of bis(aryloxy)-6-methoxy-1,3,5-triazine (2a-c).

\section{Results and Discussion}

To synthesize paramagnetic compounds $\mathbf{1 a}-\mathbf{c}$ and $\mathbf{2 a}-\mathbf{c}$, we applied a nucleophilic substitution reaction of cyanuric chloride or 2,4-dichloro-6-methoxy-1,3,5-triazine and the corresponding derivatives of spirocyclic 2,5dihydroimidazole-type monoradicals $3,{ }^{34} 4$, and 5 containing a 4-hydroxyaryl residue in the presence of a base (Figure 2). In this regard, first, we describe the preparation and structural characterization of novel nitroxides 4 and 5.
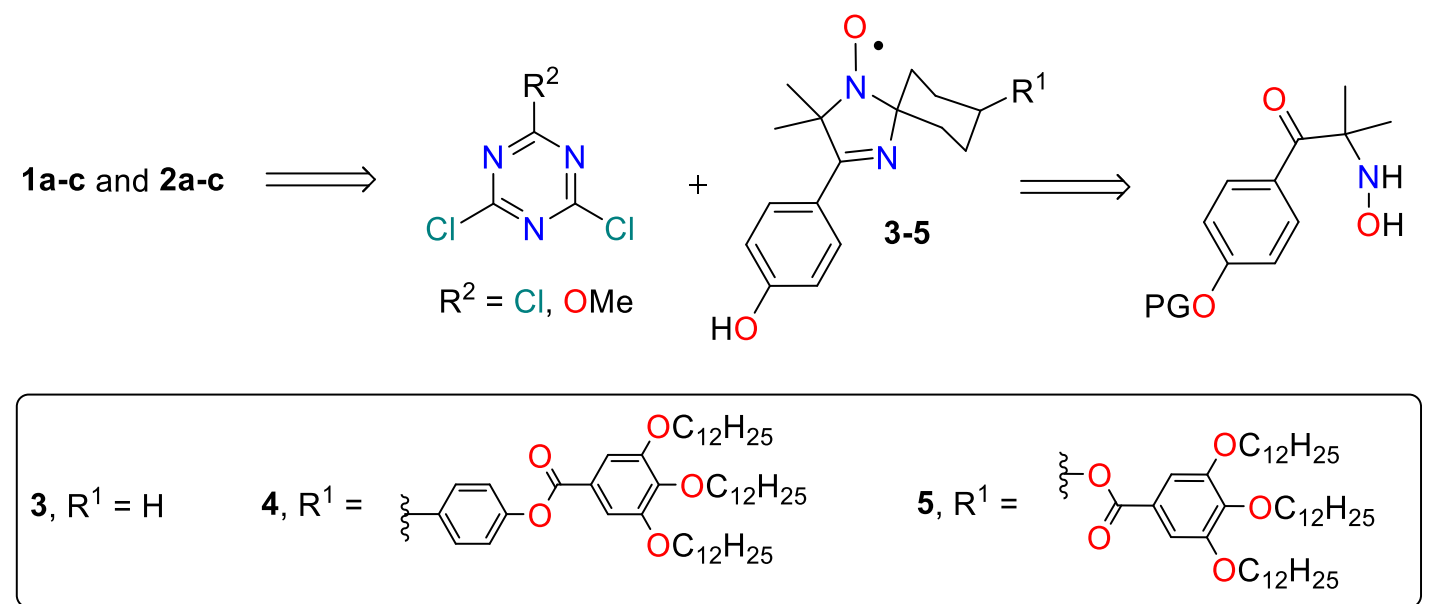

Figure 2. Retrosynthetic disconnection of target bi- and triradicals $1 \mathbf{a}-\mathbf{c}$ and $\mathbf{2 a - c .}$

Condensation of commercially available 4-(4-hydroxyphenyl)cyclohexanone (6) with 1-(4-benzyloxyphenyl)-2-(hydroxylamino)-2-methylpropan-1-one $(\mathbf{5})^{35}$ possessing a protected phenolic group proceeded with high stereoselectivity and quantitatively led to a single isomer of $\mathbf{7}$. The stereochemistry of $\mathbf{7}$ was determined by comparing its ${ }^{1} \mathrm{H}$ and ${ }^{13} \mathrm{C}$ NMR spectra with those recorded for compound $\mathbf{8}$. In our previous publication, 8 was found to have a trans-ee-configuration. ${ }^{36}$ Because the corresponding chemical shifts and coupling constants (see the Experimental section) of $\mathbf{7}$ were identical to those obtained for debenzylated analogue $\mathbf{8}$, 
we assigned the structure of a trans-ee-isomer to 7. Oxidation of hydroxylamine 7 with manganese dioxide in chloroform gave nitroxide 9 with an $80 \%$ yield. As already mentioned, tris(alkyloxy)benzoic acid derivatives can have LC properties and show columnar mesophases, ${ }^{6}$ as such, we added this mesogenic residue to our nitroxide radicals. Thus, acylation of nitroxide 9 by 3,4,5-tris(dodecyloxy)benzoic acid under Mitsunobu reaction ${ }^{37}$ conditions allowed us to obtain the desired acylated derivative $\mathbf{1 0}$ with a high yield. Debenzylation of ester 10 by hydrogenation on a palladium catalyst was always accompanied by a side reaction of reduction of the nitroxyl function to a cyclic hydroxylamine. Oxidation of the intermediate imidazoline by $\mathrm{MnO}_{2}$ in $\mathrm{CHCl}_{3}$ produced target nitroxide trans-4 containing a phenolic group with a moderate yield (Scheme 1).
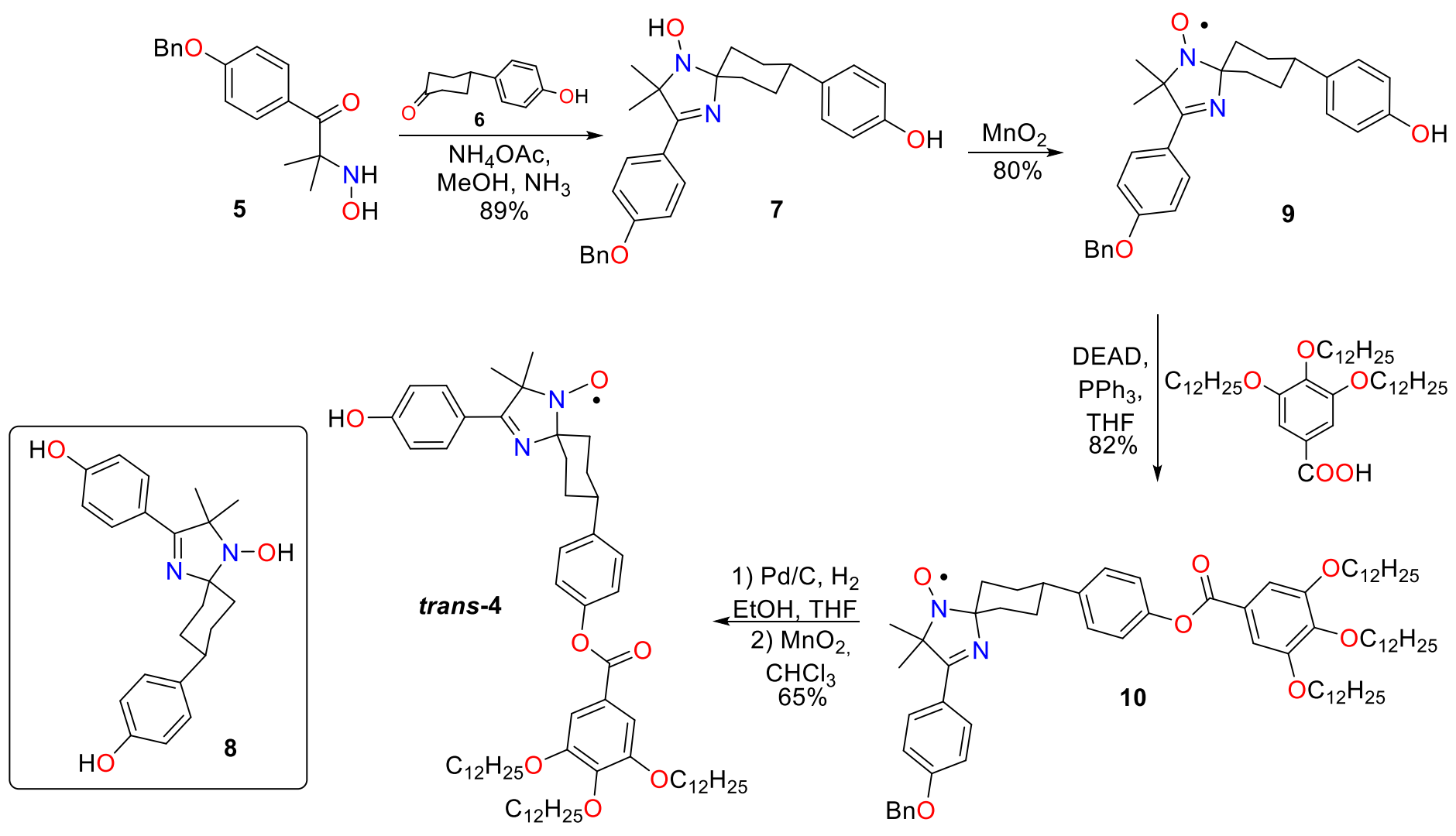

Scheme 1. The synthesis of phenolic-group-containing nitroxide trans-4.

The synthesis of the next paramagnetic phenol $\mathbf{5}$ was started from spiro-fused derivative $\mathbf{1 1}$ prepared as a diastereomeric mixture by a previously described synthetic procedure. ${ }^{35}$ The subsequent Mitsunobu acylation reaction with 3,4,5-tris(dodecyloxy)benzoic acid and separation of obtained isomers cis-12 and trans-12 by preparative thin-layer chromatography (TLC) on silica gel afforded the individual compounds cis-12 and trans12 in the ratio 5.7:1.0. To confirm the spatial structure of the obtained isomers, they were reduced in aqueous tetrahydrofuran (THF) to the corresponding diamagnetic $N$-hydroxy derivatives cis-13 and trans-13 by means of a $\mathrm{Zn} / \mathrm{NH}_{4} \mathrm{Cl}$ system. A comparison of ${ }^{1} \mathrm{H}$ and ${ }^{13} \mathrm{C}$ NMR spectra of cis-13 and trans-13 (see the Experimental section and Supporting Information) with those of previously described analogues cis-14 and trans-14 ${ }^{35}$ allowed us to identify their stereochemistry, as depicted in Scheme 2. Subsequent hydrogenation of both isomers on the palladium catalyst followed by oxidation with $\mathrm{MnO}_{2}$ in $\mathrm{CHCl}_{3}$ led to the desired 4,5dihydroimidazole derivatives cis-5 and trans-5 in moderate yields. Given that the overall yield of minor isomer trans-5 was very low, we did not subject this compound to further transformations; only isomer cis-5 was used in the next synthetic step. 


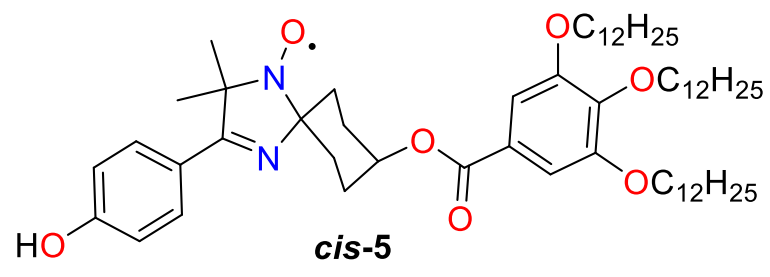

1. $\mathrm{Pd} / \mathrm{C}, \mathrm{H}_{2}, \mathrm{THF} / \mathrm{EtOH}$ 2. $\mathrm{MnO}_{2}, \mathrm{CHCl}_{3}$ $45 \%$
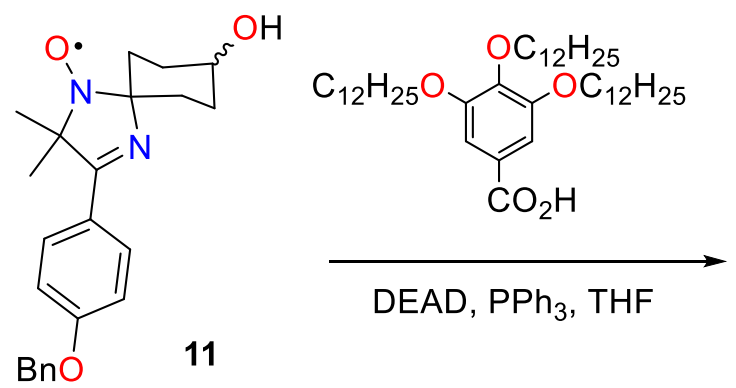

$\mathrm{BnO}$

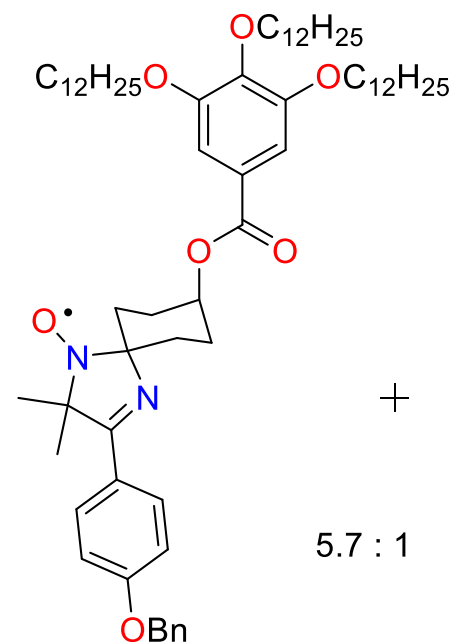

cis- $12,49 \%$

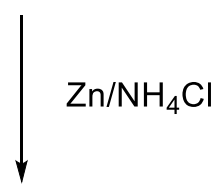<smiles>C=C(C)C1=NC2(CCC(OC(=O)c3cc(OCC)c(OCC)c(OCC)c3)C2)N([O])C1(C)C</smiles>

1. $\mathrm{Pd} / \mathrm{C}, \mathrm{H}_{2}, \mathrm{THF} / \mathrm{EtOH}$ 2. $\mathrm{MnO}_{2}, \mathrm{CHCl}_{3}$ $50 \%$

$\mathrm{BnO}$<smiles>[c-]1ccccc1</smiles>

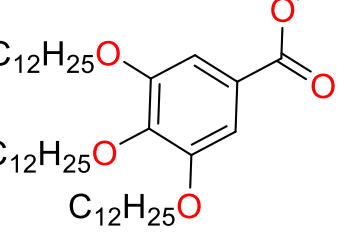

trans-12, 9\%

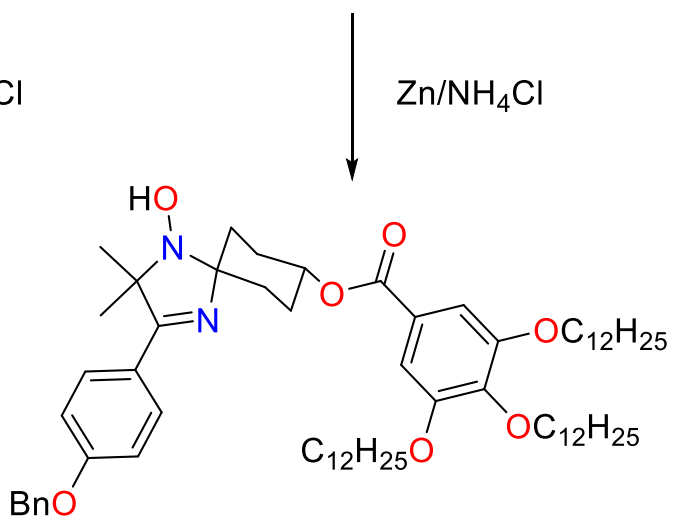

trans $-13,75 \%$

cis- $13,80 \%$<smiles>CCCCCCCCCOc1ccc(C(=O)OCC2CCC3(C2)N=C(c2ccc(OCCCC)cc2)C(C)(C)N3O)cc1</smiles>

trans-14

Scheme 2. The synthesis of phenolic-group-containing nitroxides cis-5 and trans-5. 
The final step of our synthesis was the nucleophilic substitution of chlorides from cyanuric chloride and 2,4-dichloro-6-methoxy-1,3,5-triazine, respectively via a reaction with the synthesized paramagnetic phenols. At first, we tried to carry out this reaction with compound 3, which has no substituents at position 4 of the cyclohexane ring. Because radical $\mathbf{3}$ does not contain lipophilic groups (long alkyl chains), it was possible to generate its phenolate anion in an alkaline aqueous solution. The interaction of 3 or 2 molar equivalents of this anion with 1,3,5-trichlorotriazine or 2,4-dichloro-6-methoxy-1,3,5-triazine successfully produced the corresponding tri- and biradicals $\mathbf{1 a}$ and $\mathbf{2 a}$ in 80 and $75 \%$ yields, respectively (Scheme 3 ).
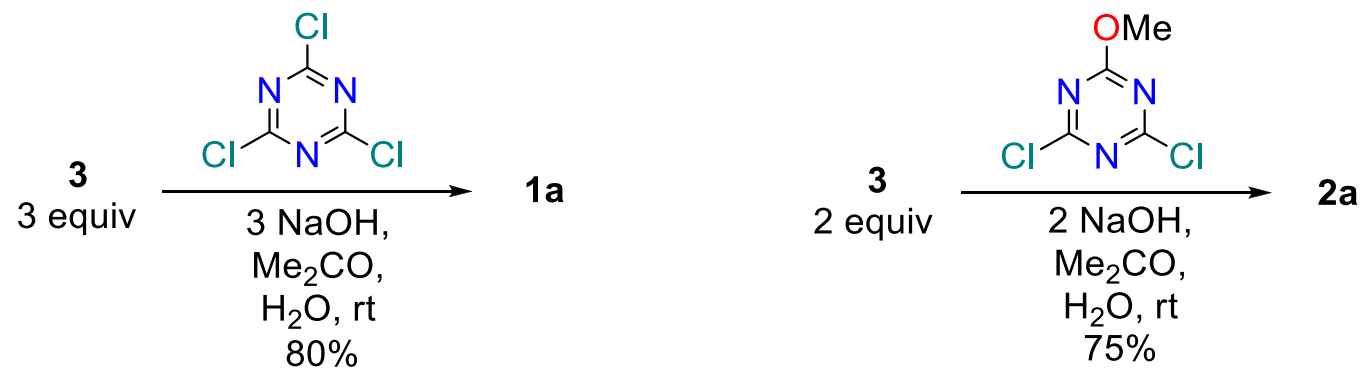

Scheme 3. The synthesis of target tri- and biradicals $1 \mathbf{a}$ and $\mathbf{2 a}$.

The crystal structure of triradical 1a was determined by the X-ray diffraction method (Figure 3). The molecules of $1 \mathrm{a}$ are located on threefold rotational axes and have $\Delta$-conformations inside the crystal. ${ }^{38}$ At the same time, phenoxy moieties of each molecule are almost perpendicular to the plane of the triazine core [torsion angle C1-O1-C2-C3: $83.4(2)^{\circ}$ ]. An analogous orientation of phenoxy groups is observed, for example, in a solvate of 2,4,6-tris(4-bromophenoxy)-1,3,5-triazine with hexamethylbenzene. ${ }^{39}$ The geometry of the 3phenyl-1,4-diazaspiro[4.5]dec-3-ene 1-oxyl moiety is almost similar to that in 2,2-dimethyl-3-[4-(decyloxy)phenyl]-1,4-diazaspiro[4.5]dec-3-ene 1-oxyl. ${ }^{34}$ The dihedral angle between the phenyl and 2,5-dihydroimidazole planes is $4.2(2)^{\circ}$. It is worth noting that the formed layers are parallel to the $a b$ plane owing to the C6-H...O2 interaction (the $\mathrm{H}$...O distance: 2.38 , the $\mathrm{C}-\mathrm{H} . . . \mathrm{O}$ angle: $140^{\circ}$ ) in the crystal packing of triradical $1 \mathrm{a}$. Moreover, inside and between the layers, there are some voids, which are filled with highly disordered solvent molecules (see the Experimental section).

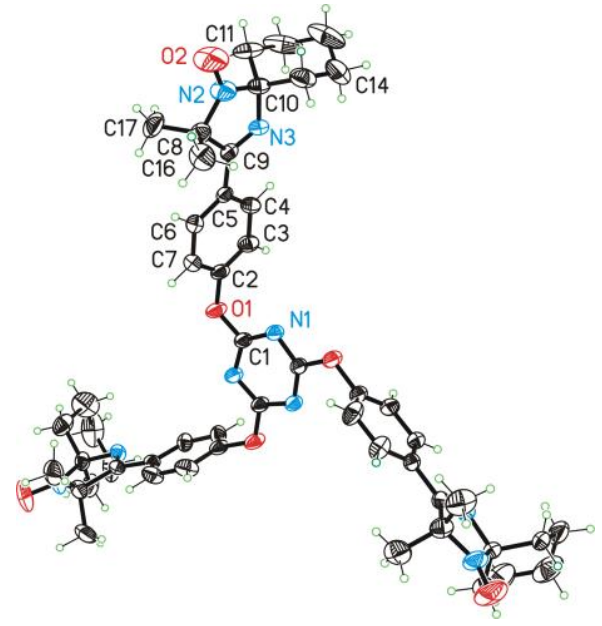

Figure 3. An ORTEP drawing of triradical 1a with $30 \%$ probability of ellipsoids. Atom labels are shown only for the asymmetric part of the molecule. 
Because we could successfully realize the coupling between unsubstituted paramagnetic derivative 3 and 1,3,5-trichlorotriazine as well as 2,4-dichloro-6-methoxy-1,3,5-triazine, we tried to conduct the same reaction with more complex and encumbered nucleophiles, such as radicals trans-4 and cis-5. Given that these compounds contain lipophilic groups, it was impossible to obtain their phenolate anions in an alkaline aqueous solution. For this reason, we chose potassium carbonate in acetone as a base medium. Because of the relatively weak basicity of the medium, boiling the mixture containing cyanuric chloride, trans-4, or cis-5 and potassium carbonate in acetone within $5 \mathrm{~h}$ gave the mixture of target triradicals $\mathbf{1 b}$ or $\mathbf{1 c}$, respectively along with disubstitution products: diradicals $\mathbf{1 5 b}$ and $\mathbf{1 5 c}$ in the ratio 2:1 with an overall yield of $60 \%$. On the other hand, such reaction incompleteness makes it in principle possible to obtain mono- and disubstitution products under the experimental conditions. The interaction between 2,4-dichloro-6-methoxy-1,3,5-triazine and nitroxides trans-4 and cis-5 enabled obtaining desired biradicals $\mathbf{2 b}$ and $\mathbf{2 c}$, respectively with a $45 \%$ yield.
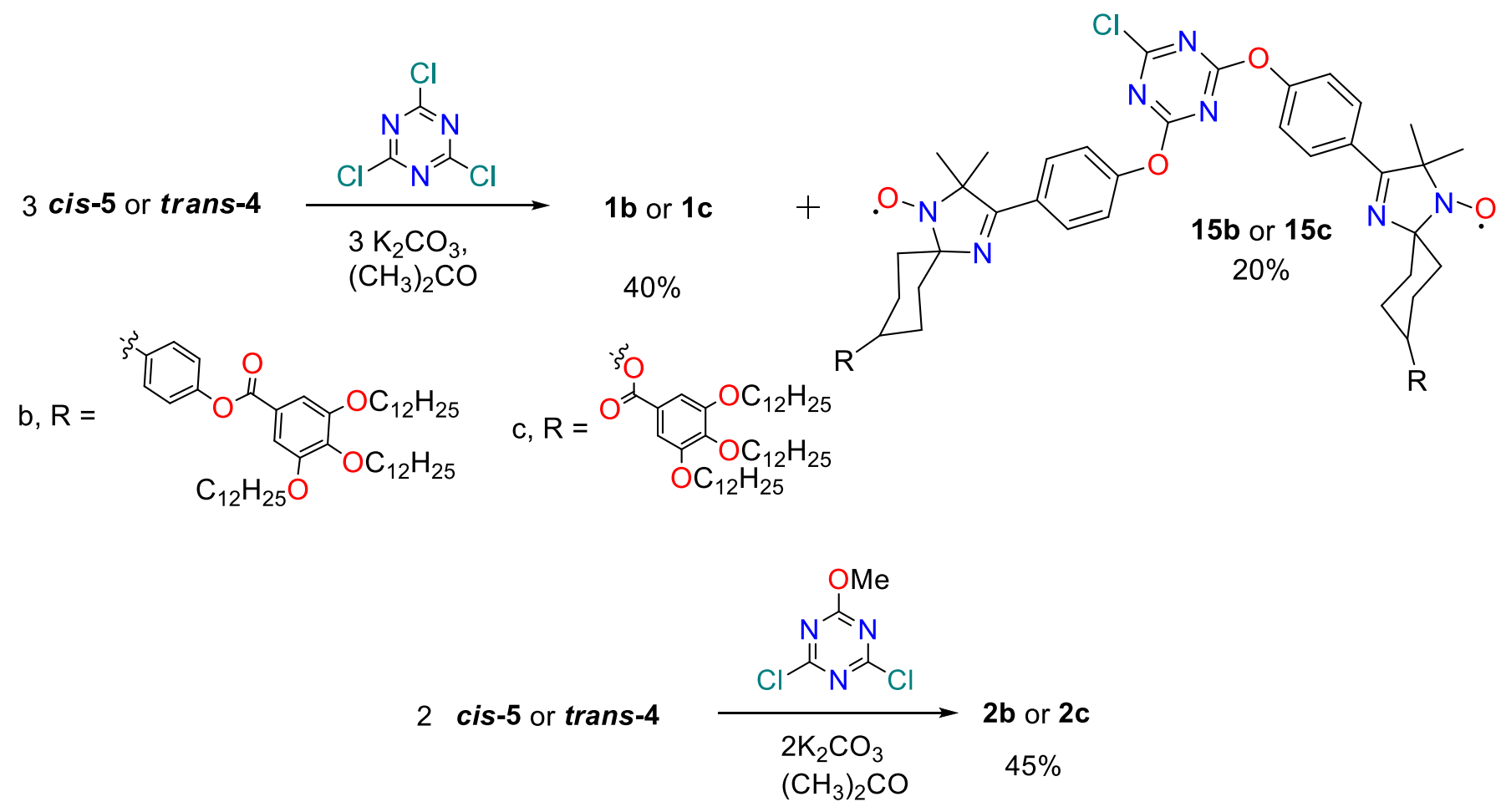

Scheme $\mathbf{4}$. The synthesis of target tri- and biradicals $\mathbf{1 b}, \mathbf{c}$ and $\mathbf{2 b , c .}$

Mono-, bi- and trinitroxides $\mathbf{1 b}, \mathbf{c}, \mathbf{2 b}, \mathbf{c}$, trans-4, trans-5, cis-5, and 15b,c containing mesogenic groups were investigated for LC properties by means differential scanning calorimetry (DSC) and optical polarizing microscope. The phase transition data determined by DSC is presented in the Table S1 (see the Supporting Information). None of the compounds possesses liquid crystalline properties. Trans-4, trans-5 and cis-5 represent pale-yellow amorphous solids and showed only crystal-to-crystal and crystal-to-isotropic liquid phase transitions. $\mathbf{1 b}, \mathbf{c}, \mathbf{2} \mathbf{b}, \mathbf{c}$ and $\mathbf{1 5 b}, \mathbf{c}$ are pale yellow waxy solids and showed no peaks in differential scanning calorimetry (DSC) curves in the temperature interval from 25 to $140{ }^{\circ} \mathrm{C}$. When the starting temperature was decreased to $-10^{\circ} \mathrm{C}$ the corresponding melting peaks appeared at the temperatures lower than $25{ }^{\circ} \mathrm{C}$ (see Table S1). No birefringent texture was observed for all the compounds by optical polarizing microscope if the temperature was higher than their melting point in the heating and in the cooling runs. It was assumed that they do not possess liquid crystalline properties as a consequence of low space fill factors of such bulky molecules. 
We developed a convenient approach to the synthesis of stable 1,3,5-triazine-based bi- and triradicals of the 2,5-dihydroimidazole series. Six new bi- and tris(nitroxides) were obtained, and symmetrical nature of the model tris(nitroxide) was confirmed by single crystal X-ray diffraction analysis. Investigation of the bi- and tris(nitroxides) containing mesogenic groups by means DSC and optical polarizing microscope revealed that none of synthesized radicals possess LC properties. Nevertheless, the proposed conditions for the nucleophilic substitution of chloride from cyanuric chloride with paramagnetic phenols allow us to expect successful syntheses of new hetero bi- and triradicals containing various structural types of paramagnetic units.

\section{Experimental Section}

General. Analytical and spectroscopic studies were performed in the Multi-Access Chemical Research Center SB RAS for spectral and analytical measurements. Melting points and DSC thermograms were obtained on an FP 81 HT METTLER TOLEDO device. Infrared (IR) spectra were acquired on a Vector-22 Bruker spectrometer in $\mathrm{KBr} .{ }^{1} \mathrm{H}$ and ${ }^{13} \mathrm{C}$ NMR spectra were recorded by means of Bruker AV-400 and AV-500 spectrometers for solutions of compounds in $\mathrm{CDCl}_{3}$ or DMSO- $d_{6}$, and chemical shifts were recorded in parts per million (ppm or $\delta)$ relative to internal standard residual solvent signals: $\mathrm{CDCl}_{3}\left(\delta_{\mathrm{H}} 7.26, \delta_{\mathrm{C}} 77.16\right)$ and DMSO- $d_{6}\left(\delta_{\mathrm{H}} 2.50, \delta_{\mathrm{C}}\right.$ 39.52). Electron spin resonance (ESR) spectra of the radicals were obtained on a Bruker 300 spectrometer for $10^{-4} \mathrm{M}$ solutions in chloroform. The reactions were monitored by TLC in silica gel on Sorbfil UV-254 plates. Column chromatography (CC) was performed in silica gel (ACROS, 0.060-0.200 mm). All the chemicals and solvents were of commercial reagent quality and used without further purification unless stated otherwise. Dry THF was obtained by distillation over a $\mathrm{LiH} \mathrm{CaH}_{2}$ (50:50) mixture. 4-(4-Hydroxyphenyl)cyclohexanone (6) was purchased from Aldrich. 3-(4-Hydroxyphenyl)-2,2-dimethyl-1,4-diazaspiro[4.5]dec-3-ene-1-oxyl (3), ${ }^{34}$ 1-(4benzyloxyphenyl)-2-(hydroxylamino)-2-methyl-1-propanone hydrochloride (5), 35 3-(4-benzyloxyphenyl)-2,2dimethyl-1,4-diazaspiro[4.5]dec-3-ene-8-ol 1-oxyl (11), ${ }^{36}$ 3,4,5-tris(dodecyloxy)benzoic acid, ${ }^{40}$ and 1-methoxy3,5-dichloro-1,3,5-triazine ${ }^{41}$ were obtained by the procedures described in the literature.

2,2-Dimethyl-3-(4-benzyloxy)phenyl)-1-hydroxy-8-(4-hydroxyphenyl)-1,4-diazaspiro[4,5]-deca-3-ene (7). A mixture of 4-(4-hydroxyphenyl)cyclohexanone (6) (1.605 g, $5.0 \mathrm{mmol}), 1$-(4-benzyloxyphenyl)-2-(hydroxylamino)-2-methylpropan-1-one hydrochloride (5) (0.950 g, $5.0 \mathrm{mmol})$, and ammonium acetate (1.560 g, 20 $\mathrm{mmol})$ in $\mathrm{MeOH}(50 \mathrm{~mL})$ saturated with ammonia was stirred at room temperature for $5 \mathrm{~h}$. The precipitate formed was filtered out and washed with water and $\mathrm{MeOH}$ to give 7 as a colorless solid (2.03 g, 89\%), which was used for the next step without further purification. An analytical sample was purified by recrystallization from EtOH to obtain 7 as a colorless powder; $\mathrm{mp} 118-120{ }^{\circ} \mathrm{C}(\mathrm{EtOH})$. IR (solid, $\left.\mathrm{KBr}, v_{\max } \mathrm{cm}^{-1}\right): 3458(\mathrm{OH})$, 1598, $1571(\mathrm{C}=\mathrm{N}) .{ }^{1} \mathrm{H}$ NMR (400 MHz, DMSO-d $\left.d_{6}\right): \delta_{\mathrm{H}} 1.37(6 \mathrm{H}, \mathrm{s}, \mathrm{Me}-11$ and Me-12), 1.48-1.55 (2H, m, H$6 e, 10 e), 1.68-1.75(2 \mathrm{H}, \mathrm{m}, \mathrm{H}-7 e, 9 e), 1.87-2.06(4 \mathrm{H}, \mathrm{m}, \mathrm{H}-6 a, 7 a, 9 a, 10 a), 2.42-2.51(1 \mathrm{H}, \mathrm{m}, \mathrm{H}-8 \mathrm{a}), 5.16(2 \mathrm{H}, \mathrm{s}$, $\left.\mathrm{CH}_{2}-1^{\prime \prime}\right), 6.68\left(2 \mathrm{H}, \mathrm{d},{ }^{3} \mathrm{~J} 8.2 \mathrm{~Hz}, \mathrm{H}-3^{\prime \prime \prime}, 5^{\prime \prime \prime}\right), 6.99-7.08\left(4 \mathrm{H}, \mathrm{m}, \mathrm{H}-2^{\prime \prime \prime}, 6^{\prime \prime \prime}, 3^{\prime}, 5^{\prime}\right), 7.32-7.50\left(5 \mathrm{H}, \mathrm{m}, \mathrm{H}-3^{\prime \prime}, 4^{\prime \prime}, 5^{\prime \prime}, 6^{\prime \prime}, 7^{\prime \prime}\right)$, $7.62(1 \mathrm{H}, \mathrm{s}, \mathrm{NO} \underline{\mathrm{H}}), 7.84\left(2 \mathrm{H}, \mathrm{d},{ }^{3} \mathrm{~J} 8.6 \mathrm{~Hz}, \mathrm{H}-2^{\prime}, 6^{\prime}\right), 9.13(1 \mathrm{H}, \mathrm{s}, \mathrm{O} \underline{\mathrm{H}}) .{ }^{13} \mathrm{C}$ NMR $\left(100 \mathrm{MHz}, \mathrm{DMSO}-d_{6}\right): \delta_{\mathrm{C}} 24.7$ (C-11, C-12), 31.7 (C-7, C-9), 36.0 (C-6, C-10), 42.6 (C-8), 69.4 (C-2), 69.6 (C-1'), 88.7 (C-5), 114.8 (C-3',C-5'), 115.1 (C-

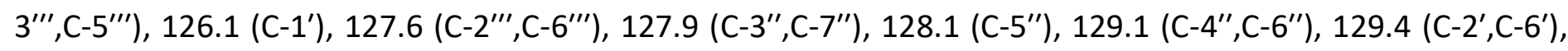
137.0 (C-2"), 137.6 (C-1"'), 155.6 (C-4'"'), 160.0 (C-4'), 171.7 (C-3). Anal. calcd for $\mathrm{C}_{29} \mathrm{H}_{32} \mathrm{~N}_{2} \mathrm{O}_{3}$ (456.58): C, 76.29; $H, 7.06 ; \mathrm{N}, 6.14$. Found: $C, 76.01 ; H, 7.01 ; \mathrm{N}, 6.14 \%$. 


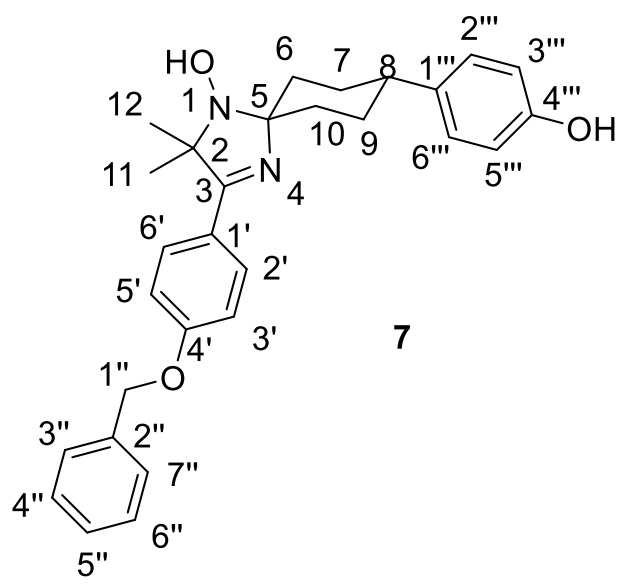

2,2-Dimethyl-3-(4-benzyloxy)phenyl-8-(4-hydroxyphenyl)-1,4-diazaspiro[4,5]deca-3-ene $\quad 1$-oxyl (9). A suspension of 2,2-dimethyl-3-(4-benzyloxy)phenyl-1-hydroxy-8-(4-hydroxyphenyl)-1,4-diazaspiro[4,5]-deca-3ene(7) (1.824 g, $4.0 \mathrm{mmol})$ and $\mathrm{MnO}_{2}(1.720 \mathrm{~g}, 20 \mathrm{mmol})$ in a $\mathrm{CHCl}_{3} / \mathrm{MeOH}(75: 25)$ mixture $(50 \mathrm{~mL})$ at room temperature was stirred for $3 \mathrm{~h}$. An excess of the oxidant was filtered out, and the solvent was evaporated. The residue was purified by CC (hexane/EtOAc, 2:1) to obtain the title compound 9 as a pale yellow powder (1.456 g, 80\%); mp 220-222 ${ }^{\circ} \mathrm{C}$ (hexane). IR (solid, $\mathrm{KBr}, v_{\max }, \mathrm{cm}^{-1}$ ): $3197(\mathrm{OH}), 1608,1591$ (C=N). ESR: t, $\mathrm{A}_{\mathrm{N}}$ $1.45 \mathrm{mT}$, giso 2.0058. Anal. calcd for $\mathrm{C}_{29} \mathrm{H}_{31} \mathrm{~N}_{2} \mathrm{O}_{3}$ (455.57): C, 76.46; $\mathrm{H}, 6.86 ; \mathrm{N}, 6.15$. Found: $\mathrm{C}, 76.40 ; \mathrm{H}, 6.75 ; \mathrm{N}$, $6.14 \%$.

4-[(5r,8r)-3-(4-Benzyloxyphenyl)-2,2-dimethyl-1-oxido-1,4-diazaspiro[4.5]dec-1-en-8-yl]phenyl 3,4,5-tris(dodecyloxy)benzoate (10). A round-bottom flask was filled with argon, then charged with compound 8 (455 mg, $1 \mathrm{mmol}$ ), $\mathrm{Ph}_{3} \mathrm{P}$ (576 mg, $2.2 \mathrm{mmol}$ ), 3,4,5-tris(dodecyloxy)benzoic acid (1.350 g, $2.0 \mathrm{mmol}$ ), and dry THF (10 $\mathrm{mL}$ ). Diethyl azodicarboxylate (DEAD) $(348 \mathrm{mg}, 2.0 \mathrm{mmol}$ ) was added to the resulting solution followed by stirring at room temperature for $24 \mathrm{~h}$. The mixture was concentrated in vacuum, the residue was triturated with $\mathrm{Et}_{2} \mathrm{O}$, cooled to $0{ }^{\circ} \mathrm{C}$, and the precipitate was filtered off. Evaporation of the solvent gave a solid, which was purified by preparative TLC on silica gel with hexane/EtOAc (80:20) to give the title compound 10 as a pale yellow solid (911 mg, 82\%), which was used for the next step without further purification. An analytical sample was prepared by recrystallization from EtOH to obtain ester 10 as a pale yellow amorphous solid $\mathrm{mp} 38-40{ }^{\circ} \mathrm{C}$ (EtOH). IR (solid, $\left.\mathrm{KBr}, v_{\max }, \mathrm{cm}^{-1}\right)$ : $1747(\mathrm{C}=\mathrm{O}), 1587(\mathrm{C}=\mathrm{N})$. ESR: t, $\mathrm{A}_{\mathrm{N}} 1.45 \mathrm{mT}, \mathrm{g}_{\text {iso }}$ 2.0058. Anal. calcd for $\mathrm{C}_{72} \mathrm{H}_{107} \mathrm{~N}_{2} \mathrm{O}_{7}$ (1112.63): $\mathrm{C}, 77.72 ; \mathrm{H}, 9.69 ; \mathrm{N}, 2.52$. Found: $\mathrm{C}, 77.42 ; \mathrm{H}, 9.63 ; \mathrm{N}, 2.50 \%$.

4-[(5r,8r)-3-(4-Hydroxyphenyl)-2,2-dimethyl-1-oxido-1,4-diazaspiro[4.5]dec-1-en-8-yl]phenyl 3,4,5-tris(dodecyloxy)benzoate (trans-4). A catalyst (4\% Pd/C) $(300 \mathrm{mg})$ was added to a solution of nitroxide 9 (889 mg, 0.8 $\mathrm{mmol})$ in a mixture of EtOH $(8 \mathrm{~mL})$ and THF $(16 \mathrm{~mL})$. The flask was purged with Ar in an Ar atmosphere, then once with $\mathrm{H}_{2}$, and the reaction mixture was hydrogenated under 1-bar pressure at $20{ }^{\circ} \mathrm{C}$ for $3.5 \mathrm{~h}$ with stirring. The catalyst was filtered off and washed with THF/EtOH (2:1). The filtrate and washings were combined, and the solvent was evaporated. The residue was dissolved in chloroform $(20 \mathrm{~mL})$, and the solution was mixed with $\mathrm{MnO}_{2}$ (344 mg, $4 \mathrm{mmol}$ ) and stirred for $3 \mathrm{~h}$ at $20^{\circ} \mathrm{C}$. The excess oxidant was filtered out, the solvent was removed in vacuum, and the residue was purified by CC (hexane/EtOAc, 80:20) to obtain the title compound trans-4 as a pale yellow amorphous solid (531 mg, 65\%). There are two peaks in the DSC curve on the heating run: at 78 and $96{ }^{\circ} \mathrm{C}$. IR (solid, $\mathrm{KBr}, v_{\max }, \mathrm{cm}^{-1}$ ): $1745(\mathrm{C}=\mathrm{O}), 1587(\mathrm{C}=\mathrm{N})$. ESR: $\mathrm{t}, \mathrm{A}_{\mathrm{N}} 1.45 \mathrm{mT}$, giso 2.0058. Anal. calcd for $\mathrm{C}_{76} \mathrm{H}_{101} \mathrm{~N}_{2} \mathrm{O}_{7}$ (1022.51): $\mathrm{C}, 76.35 ; \mathrm{H}, 9.96 ; \mathrm{N}, 2.74$. Found: $\mathrm{C}, 76.51 ; \mathrm{H}, 9.90 ; \mathrm{N}, 2.78 \%$.

Cis- and trans- 2-(4-Benzyloxyphenyl)-3,3-dimethyl-4-oxido-1,4-diazaspiro[4.5]dec-1-en-8-yl 3,4,5-tris(dodecyloxy)benzoate (12). A round-bottom flask was purged with Ar, then charged with 3-(4-benzyloxyphenyl)2,2-dimethyl-1,4-diazaspiro[4.5] dec-3-ene-8-ol 1-oxyl (11) (378 mg, 1.0 mmol), Ph ${ }_{3} \mathrm{P}$ (576 mg, $2.2 \mathrm{mmol}$ ), 
3,4,5-tris(dodecyloxy)benzoic acid (1.350 g, $2.0 \mathrm{mmol}$ ), and THF (10 mL). DEAD (348 mg, $2.0 \mathrm{mmol}$ ) was added to the resultant solution followed by stirring at room temperature for $24 \mathrm{~h}$. The mixture was concentrated in vacuum, and the residue was triturated with $\mathrm{Et}_{2} \mathrm{O}$ and cooled to $0{ }^{\circ} \mathrm{C}$. The precipitate was filtered off. The solvent was removed, and the residue was subjected to chromatography (preparative TLC) on silica gel (hexane/EtOAc, 5:1), with collection of the fractions with $R_{f} 0.30$ (cis isomer) and $R_{f} 0.35$ (trans isomer). The total yield was $58 \%$.

(5s,8s)-2-(4-Benzyloxyphenyl)-4-oxido-3,3-dimethyl-1,4-diazaspiro[4.5]dec-1-en-8-yl 3,4,5-tris(dodecyloxy)benzoate (cis-12). Pale yellow amorphous solid (507 mg, 49\%); mp 66-68 ${ }^{\circ} \mathrm{C}$ (EtOH). IR (solid, $\mathrm{KBr}, v_{\max }, \mathrm{cm}^{-1}$ : 1705 (C=O), 1608, 1591 (C=N). ESR: $t, A_{N} 1.45 \mathrm{mT}, g_{\text {iso }}$ 2.0058. Anal. calcd for $\mathrm{C}_{66} \mathrm{H}_{103} \mathrm{~N}_{2} \mathrm{O}_{7}$ (1036.53): C, 76.48; $H, 10.02 ; N, 2.70$. Found: $C, 76.56 ; H, 9.95 ; N, 2.78 \%$.

(5s,8s)-2-(4-Benzyloxyphenyl)-4-oxido-3,3-dimethyl-1,4-diazaspiro[4.5]dec-1-en-8-yl 3,4,5-tris(dodecyloxy)benzoate (trans-12). Pale yellow amorphous solid (93 mg, 9\%); mp 50-52 ${ }^{\circ} \mathrm{C}(\mathrm{EtOH})$. IR (solid, $\mathrm{KBr}, v_{\max }, \mathrm{cm}^{-1}$ ): 1751 (C=O), 1607, 1591 (C=N). ESR: $t, A_{N} 1.45 \mathrm{mT}, g_{\text {iso }}$ 2.0058. Anal. calcd for $\mathrm{C}_{66} \mathrm{H}_{103} \mathrm{~N}_{2} \mathrm{O}_{7}$ (1036.53): C, 76.48; $H, 10.02 ; \mathrm{N}, 2.70$. Found: C, 76.45; $\mathrm{H}, 9.95 ; \mathrm{N}, 2.80 \%$.

(5s,8s)-2-(4-Benzyloxyphenyl)-4-hydroxy-3,3-dimethyl-1,4-diazaspiro[4.5]dec-1-en-8-yl 3,4,5-tris(dodecyloxy)benzoate (cis-13). A solution of nitroxide cis-12 (52 mg, $0.05 \mathrm{mmol})$ in THF (1 mL) was treated with zinc dust $(5 \mathrm{mg}, 0.075 \mathrm{mmol})$, then a solution of $\mathrm{NH}_{4} \mathrm{Cl}(5 \mathrm{mg}, 0.1 \mathrm{mmol})$ in $\mathrm{H}_{2} \mathrm{O}(20 \mu \mathrm{L})$ was added to the resulting suspension, and the reaction mixture was stirred for $1 \mathrm{~h}$ at $20^{\circ} \mathrm{C}$ under Ar. The $\mathrm{Zn} / \mathrm{ZnO}$ cake was removed by filtration, the filtrate was concentrated, and the residue was triturated with $\mathrm{EtOH}$. The precipitate that formed was filtered off and washed with $\mathrm{EtOH}$ to obtain cis-13 as a colorless powder $(41 \mathrm{mg}, 80 \%) ; \mathrm{mp} 78-80{ }^{\circ} \mathrm{C}$ (EtOH). IR (solid, $\left.\mathrm{KBr}, v_{\max }, \mathrm{cm}^{-1}\right): 1706(\mathrm{C}=0), 1607,1591(\mathrm{C}=\mathrm{N}) .{ }^{1} \mathrm{H}$ NMR $\left(400 \mathrm{MHz}, \mathrm{DMSO}-d_{6}+\mathrm{CDCl}_{3}\right): \delta_{\mathrm{H}} 0.81-$ $0.86\left(9 \mathrm{H}, \mathrm{m}, 3 \mathrm{CH}_{3}\right), 1.16-1.35\left(48 \mathrm{H}, \mathrm{m}, 24 \mathrm{CH}_{2}\right), 1.39(6 \mathrm{H}, \mathrm{s}, \mathrm{Me}-11$ and Me-12), 1.40-1.42 (2H, m, H-6e,10e), 1.41-1.49 $\left(6 \mathrm{H}, \mathrm{m}, 3 \mathrm{CH}_{2}\right), 1.60-1.68\left(2 \mathrm{H}, \mathrm{m}, \mathrm{OCH}_{2} \mathrm{C}_{2}\right), 1.70-1.78\left(4 \mathrm{H}, \mathrm{m}, 2 \mathrm{OCH}_{2} \mathrm{C}_{2}\right), 1.88-1.98(2 \mathrm{H}, \mathrm{m}, \mathrm{H}-7 e, 9 e)$, 2.02-2.12 (2H, m, H-7a,9a), 2.24-2.34 (2H, m, H-6a,10a), 3.89-3.93 (2H, m, OCㅡㅡㄹ $\left.\mathrm{CH}_{2}\right), 3.93-4.20(4 \mathrm{H}, \mathrm{m}$, $\left.20 \mathrm{CH}_{2} \mathrm{CH}_{2}\right), 5.11\left(2 \mathrm{H}, \mathrm{s}, \mathrm{CH}_{2}-1^{\prime \prime}\right), 5.15-5.19(1 \mathrm{H}, \mathrm{m}, \mathrm{H}-8 e), 7.00\left(2 \mathrm{H}, \mathrm{d}, 3^{3} \mathrm{~s} .3 \mathrm{~Hz}, \mathrm{H}-3^{\prime}, 5^{\prime}\right), 7.22\left(2 \mathrm{H}, \mathrm{s}, \mathrm{H}-3^{\prime \prime \prime}, 7^{\prime \prime \prime}\right)$, 7.25-7.40 (5H, m, H-3", $\left.4^{\prime \prime}, 5^{\prime \prime}, 6^{\prime \prime}, 7^{\prime \prime}\right), 7.78\left(2 \mathrm{H}, \mathrm{d},{ }^{3} \mathrm{~J} 8.3 \mathrm{~Hz}, \mathrm{H}-2^{\prime}, 6^{\prime}\right), 8.11(1 \mathrm{H}, \mathrm{s}, \mathrm{NO} \underline{\mathrm{H}}) .{ }^{13} \mathrm{C} \mathrm{NMR}(100 \mathrm{MHz}$, DMSO- $\left.d_{6}+\mathrm{CDCl}_{3}\right): \delta_{\mathrm{C}}$ spiro system and aryl carbon signals: 25.1 (C-11, C-12), 27.8 (C-7, C-9), 30.3 (C-6, C-10),

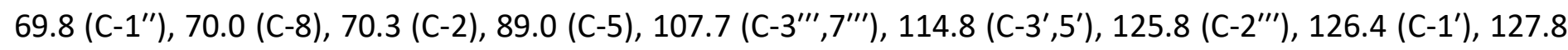
$\left(C-3^{\prime \prime}, 7^{\prime \prime}\right), 128.1\left(C-5^{\prime \prime}\right), 128.7\left(C-2^{\prime}, 6^{\prime}\right), 129.5$ (C-4", C-6"), $137.0\left(C-2^{\prime \prime}\right), 141.8$ (C-5"'), $152.8\left(C-4^{\prime \prime \prime}, 6^{\prime \prime \prime}\right), 160.1$ $\left(\mathrm{C}-4^{\prime}\right), 165.0$ (C-1'"'), 172.4 (C-3); lateral alkyl chain carbon signals: $14.4\left(\mathrm{CH}_{3}\right), 22.6,26.1,26.2,29.2,29.3$, 29.51, 29.55, 29.61, 29.63, 29.65, 29.7, 30.9, 31.8, $68.9\left(\mathrm{OCL}_{2} \mathrm{CH}_{2}\right), 73.1\left(\mathrm{OCh}_{2} \mathrm{CH}_{2}\right)$. Anal. calcd for $\mathrm{C}_{66} \mathrm{H}_{104} \mathrm{~N}_{2} \mathrm{O}_{7}$ (1037.54): C, 76.40; H, 10.10; N, 2.70. Found: C, 76.50; H, 9.98; N, 2.71\%. 


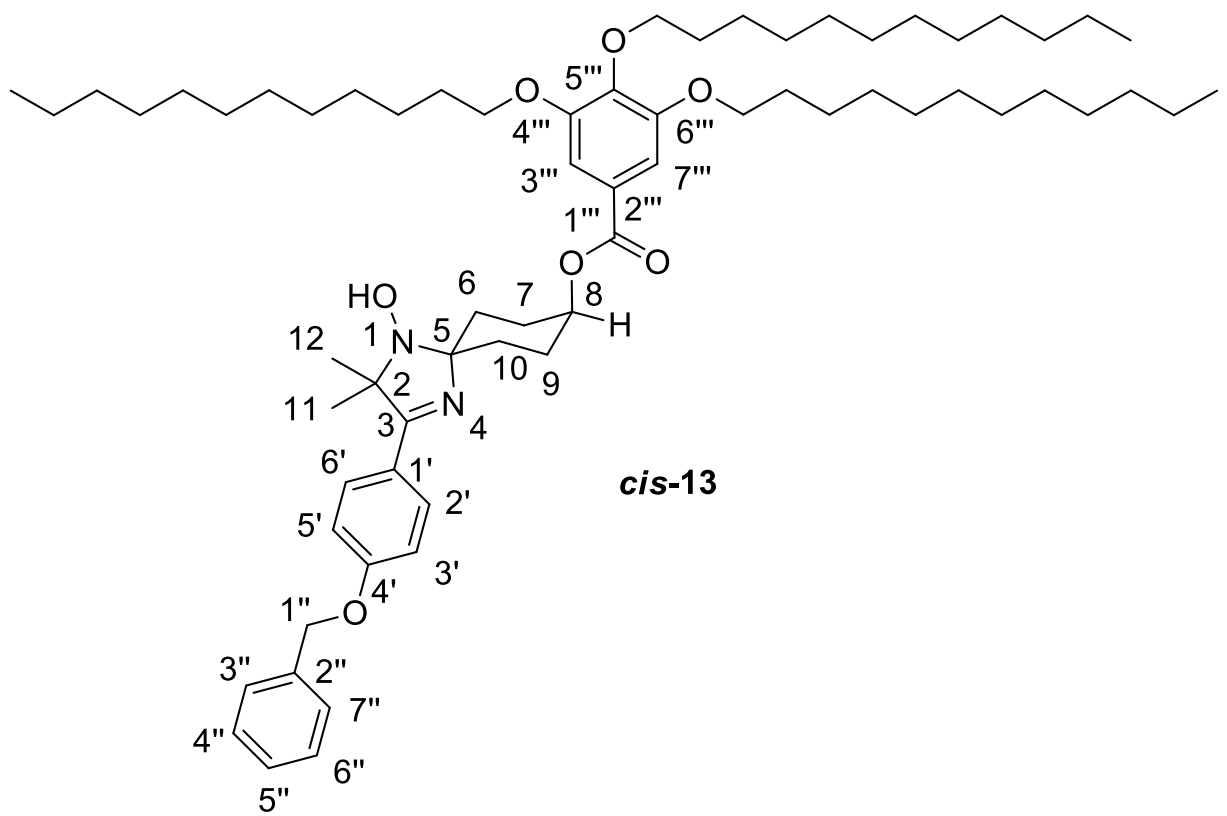

(5r,8r)-2-(4-Benzyloxyphenyl)-4-hydroxy-3,3-dimethyl-1,4-diazaspiro[4.5]dec-1-en-8-yl 3,4,5-tris(dodecyloxy)benzoate (trans-13) was obtained analogously to cis-isomer 13 via reduction of compound trans-12.

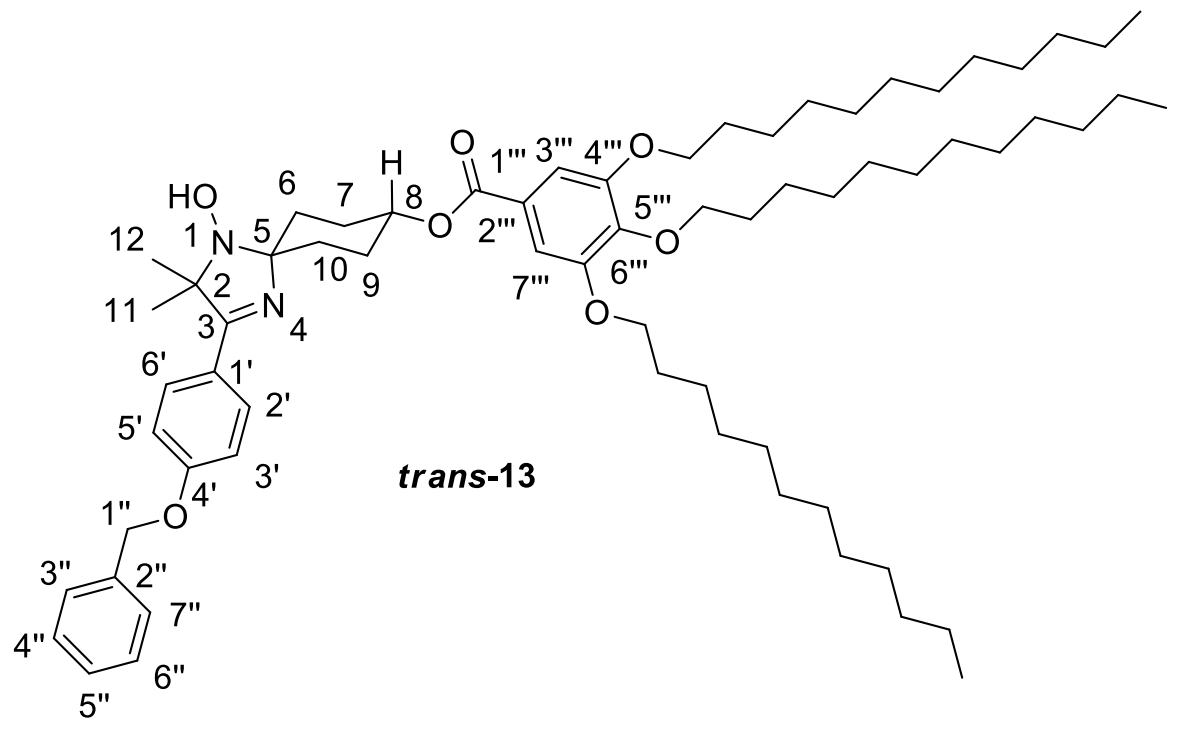

A colorless powder (38 mg, 75\%); mp 58-60 ${ }^{\circ} \mathrm{C}(\mathrm{EtOH})$. IR (solid, $\mathrm{KBr}, v_{\max }, \mathrm{cm}^{-1}$ ): 1748 (C=O), 1608, 1591 $(\mathrm{C}=\mathrm{N}) .{ }^{1} \mathrm{H}$ NMR $\left(400 \mathrm{MHz}, \mathrm{DMSO}-d_{6}+\mathrm{CDCl}_{3}\right): \delta_{\mathrm{H}} 0.80-0.86\left(9 \mathrm{H}, \mathrm{m}, 3 \mathrm{CH}_{3}\right), 1.16-1.35\left(48 \mathrm{H}, \mathrm{m}, 24 \mathrm{CH}_{2}\right), 1.38(6 \mathrm{H}, \mathrm{s}$, Me-11 and Me-12), 1.40-1.50 (6H, m, 3CH $), 1.52-1.58(2 \mathrm{H}, \mathrm{m}, \mathrm{H}-6 e, 10 e), 1.59-1.68\left(2 \mathrm{H}, \mathrm{m}, \mathrm{OCH}_{2} \mathrm{CH}_{2}\right), 1.68-$ $1.79\left(4 \mathrm{H}, \mathrm{m}, 2 \mathrm{OCH}{ }_{2} \underline{\mathrm{H}}_{2}\right), 1.97-2.07(6 \mathrm{H}, \mathrm{m}, \mathrm{H}-7 e, 9 e, 7 a, 9 a, 6 a, 10 a), 3.87-3.94\left(2 \mathrm{H}, \mathrm{m}, \mathrm{OC}_{2} \mathrm{CH}_{2}\right), 3.94-4.30$ $\left(4 \mathrm{H}, \mathrm{m}, 2 \mathrm{OC} \mathrm{H}_{2} \mathrm{CH}_{2}\right), 4.84-4.95(1 \mathrm{H}, \mathrm{m}, \mathrm{H}-8 a), 5.12\left(2 \mathrm{H}, \mathrm{s}, \mathrm{CH}_{2}-1^{\prime \prime}\right), 7.00\left(2 \mathrm{H}, \mathrm{d}, 3\right.$ J $\left.7.5 \mathrm{~Hz}, \mathrm{H}-3^{\prime}, 5^{\prime}\right), 7.17(2 \mathrm{H}, \mathrm{s}, \mathrm{H}-$ $\left.3^{\prime \prime \prime}, 7^{\prime \prime \prime}\right), 7.25-7.49\left(5 \mathrm{H}, \mathrm{m}, \mathrm{H}-3^{\prime \prime}, 4^{\prime \prime}, 5^{\prime \prime}, 6^{\prime \prime}, 7^{\prime \prime}\right), 7.58(1 \mathrm{H}, \mathrm{s}, \mathrm{NOH}), 7.80\left(2 \mathrm{H}, \mathrm{d}, 3^{3} \mathrm{~J} 7.5 \mathrm{~Hz}, \mathrm{H}-2^{\prime}, 6^{\prime}\right) .{ }^{13} \mathrm{C}$ NMR (100 $\mathrm{MHz}$, DMSO- $\left.d_{6}+\mathrm{CDCl}_{3}\right): \delta_{\mathrm{C}}$ spiro system and aryl carbon signals: 24.5 (C-11, C-12), 28.5 (C-7, C-9), 33.2 (C-6, C-

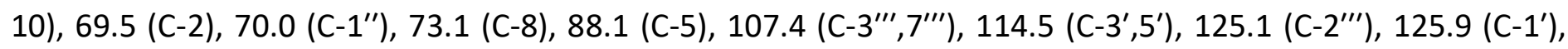

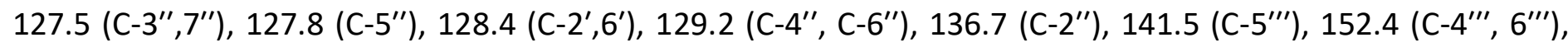
159.8 (C-4'), 164.9 (C-1"')), 172.1 (C-3); lateral alkyl chain carbon signals: $13.9\left(3 \mathrm{CH}_{3}\right), 22.2,25.6,25.7,28.85$, 28.91, 29.10, 29.17, 29.20, 29.25, 29.3, 29.9, 31.4, 31.8, $68.6\left(\mathrm{O}_{\mathrm{C}} \mathrm{CH}_{2}\right), 72.7\left(\mathrm{OCH}_{2} \mathrm{CH}_{2}\right)$. Anal. calcd for $\mathrm{C}_{66} \mathrm{H}_{104} \mathrm{~N}_{2} \mathrm{O}_{7}$ (1037.54): C, 76.40; $\mathrm{H}, 10.10 ; \mathrm{N}, 2.70$. Found: $\mathrm{C}, 76.52 ; \mathrm{H}, 9.95 ; \mathrm{N}, 2.72 \%$. 

benzoate (cis-5). The catalyst (4\% Pd/C) (100 mg) was added to a solution of nitroxide cis-12 (316 mg, 0.3 $\mathrm{mmol})$ in a mixture of EtOH $(7 \mathrm{~mL})$ and THF $(7 \mathrm{~mL})$, the flask was purged with Ar in an Ar atmosphere, then once with $\mathrm{H}_{2}$, and the reaction mixture was hydrogenated under 1-bar pressure at $20^{\circ} \mathrm{C}$ for $3 \mathrm{~h}$ with stirring. The catalyst was filtered off and washed with THF/EtOH (50:50). The filtrate and washings were combined, and the solvent was evaporated. The residue was dissolved in chloroform (15 mL), and the solution was mixed with $\mathrm{MnO}_{2}(129 \mathrm{mg}, 1.5 \mathrm{mmol})$ and stirred for $3 \mathrm{~h}$ at $20^{\circ} \mathrm{C}$. The excess oxidant was filtered out, the solvent was removed in vacuum, and the residue was purified by CC (hexane/EtOAc, 75:25) to obtain nitroxide cis-5 as a pale yellow amorphous solid (128 mg, 45\%); mp 62-64 ${ }^{\circ} \mathrm{C}$ (EtOH). IR (solid, KBr, $v_{\max }, \mathrm{cm}^{-1}$ ): 3437 (OH), 1703 $(\mathrm{C}=\mathrm{O}), 1612,1598$ (C=N). ESR: $\mathrm{t}, A_{\mathrm{N}} 1.45 \mathrm{mT}, g_{\text {iso }}$ 2.0058. Anal. calcd for $\mathrm{C}_{59} \mathrm{H}_{97} \mathrm{~N}_{2} \mathrm{O}_{7}$ (946.41): $\mathrm{C}, 74.88 ; \mathrm{H}, 10.33$; $\mathrm{N}, 2.96$. Found: $\mathrm{C}, 74.73 ; \mathrm{H}, 10.30 ; \mathrm{N}, 3.02 \%$.

(5r,8r)-2-(4-Hydroxyphenyl)-4-oxido-3,3-dimethyl-1,4-diazaspiro[4.5]dec-1-en-8-yl 3,4,5-tris(dodecyloxy)benzoate (trans-5) was obtained similarly to nitroxide cis-5 from compound trans-12. A pale amorphous solid (141 mg, 50\%); mp 80-82 ${ }^{\circ} \mathrm{C}$ (EtOH). IR (solid, KBr, $v_{\max }, \mathrm{cm}^{-1}$ ): $3388(\mathrm{OH}), 1697$ (C=O), 1608, 1587 (C=N). ESR: $\mathrm{t}, A_{\mathrm{N}} 1.45 \mathrm{mT}, g_{\text {iso }}$ 2.0058. Anal. calcd for $\mathrm{C}_{59} \mathrm{H}_{97} \mathrm{~N}_{2} \mathrm{O}_{7}$ (946.41): C, 74.88; $\mathrm{H}, 10.33 ; \mathrm{N}, 2.96$. Found: $\mathrm{C}, 74.75 ; \mathrm{H}$, $10.25 ; \mathrm{N}, 2.95 \%$.

\section{4,4', 4'"-[4,4',4"'-(1,3,5-Triazine-2,4,6-triyl)tris(oxy)tris(benzene-4,1-diyl)]tris(5,5-dimethyl-2,2-pentamethyl-} en-1-oxido-2,5-dihydro-1H-imidazole) (1a). The solution of sodium phenoxide obtained by dissolving 3-(4hydroxyphenyl)-2,2-dimethyl-1,4-diazaspiro[4.5]dec-3-en-1-oxyl (3) (84 mg, $0.31 \mathrm{mmol}$ ) in $1 \mathrm{~mL}$ of aqueous $0.3 \mathrm{~N} \mathrm{NaOH}$ was gradually added to the mixture of $18 \mathrm{mg}(0.1 \mathrm{mmol})$ of cyanuric chloride and $2 \mathrm{~mL}$ of acetone during vigorous stirring. After stirring for $3 \mathrm{~h}$ at room temperature, acetone was evaporated, and the crystal precipitate was filtered off, washed with water, and air dried. The crude product was purified by CC (hexane/EtOAc, 2:1) to prepare trinitroxide 1a as a yellow powder (71 mg, 80\%); mp 146-148 ${ }^{\circ} \mathrm{C}$ (hexane). Single crystals for $\mathrm{X}$-ray analysis were obtained by recrystallization of compound 1a from hexane/EtOAc (75:25). IR (solid, $\mathrm{KBr}, v_{\max }, \mathrm{cm}^{-1}$ ): 1606, 1566 (C=N). ESR: t, $\mathrm{A}_{\mathrm{N}} 1.45 \mathrm{mT}, g_{\text {iso }}$ 2.0058. Anal. calcd for $\mathrm{C}_{51} \mathrm{H}_{60} \mathrm{~N}_{9} \mathrm{O}_{6}$ (895.08): C, 68.43; H, 6.76; N, 14.08. Found: C, 68.33; H, 6.81; N, 13.98\%.

\section{4,4'-[4,4'-(6-Methoxy-1,3,5-triazine-2,4-diyl)bis(oxy)bis(4,1-phenylene)]bis(5,5-dimethyl-2,2-pentamethylen-} 1-oxido-2,5-dihydro-1H-imidazole) (2a) was obtained similarly to nitroxide 1 a from $18 \mathrm{mg}(0.1 \mathrm{mmol})$ of 2,4dichloro-6-methoxy-1,3,5-triazine, $57 \mathrm{mg}(0.21 \mathrm{mmol})$ of phenol 3, and $8 \mathrm{mg}(0.21 \mathrm{mmol})$ of sodium hydroxide in a solution in water/acetone (1:2). The crude solid was recrystallized from hexane/EtOAc to obtain $\mathbf{2 a}$ as a yellow powder (48 mg, 75\%); mp 73-75 ${ }^{\circ} \mathrm{C}$. IR (solid, $\mathrm{KBr}, v_{\max }, \mathrm{cm}^{-1}$ ): 1606, 1570 (C=N). ESR: $\mathrm{t}, A_{\mathrm{N}} 1.45 \mathrm{mT}, g_{\text {iso }}$ 2.0058. Anal. calcd for $\mathrm{C}_{36} \mathrm{H}_{43} \mathrm{~N}_{7} \mathrm{O}_{5}$ (653.77): $\mathrm{C}, 66.14 ; \mathrm{H}, 6.63 ; \mathrm{N}, 15.00$. Found: $\mathrm{C}, 66.00 ; \mathrm{H}, 6.53 ; \mathrm{N}, 14.90 \%$.

Trinitroxide (1b) and binitroxide (15b). A mixture of $168 \mathrm{mg}(0.165 \mathrm{mmol})$ 4-[(5r,8r)-3-(4-hydroxyphenyl)-2,2dimethyl-1-oxido-1,4-diazaspiro[4.5]dec-1-en-8-yl]phenyl 3,4,5-tris(dodecyloxy)benzoate (trans-4), 9 mg (0.05 $\mathrm{mmol})$ cyanuric chloride, and $22 \mathrm{mg}(0.165 \mathrm{mmol})$ of potassium carbonate in $2 \mathrm{~mL}$ of dry acetone was refluxed for $5 \mathrm{~h}$. The solvent was evaporated, and the residue was mixed with water $(4 \mathrm{~mL})$ and chloroform $(10 \mathrm{~mL})$. The organic layer was separated, washed with water, and dried over magnesium sulfate. The organic filtrate was condensed in vacuum, and the residue was separated into individual compounds by CC (hexane/EtOAc, 75:25) to obtain compound $\mathbf{1 b}\left(R_{f} 0.50\right)$ and compound $\mathbf{1 5 b}\left(R_{f} 0.20\right)$ in that order.

Trinitroxide (1b). A yellow waxy solid. Yield: $62 \mathrm{mg}$ (40\%). There are no peaks in the DSC curve on the heating run. IR (solid, $\mathrm{KBr}, v_{\max }, \mathrm{cm}^{-1}$ ): 1762, $1733(\mathrm{C}=\mathrm{O}), 1585,1558(\mathrm{C}=\mathrm{N})$. ESR: $\mathrm{t}, A_{\mathrm{N}} 1.45 \mathrm{mT}, g_{\text {iso }}$ 2.0058. Anal. calcd for $\mathrm{C}_{198} \mathrm{H}_{300} \mathrm{~N}_{9} \mathrm{O}_{21}$ (3142.65): $\mathrm{C}, 75.67 ; \mathrm{H}, 9.62 ; \mathrm{N}, 4.01$. Found: $\mathrm{C}, 75.50 ; \mathrm{H}, 9.80 ; \mathrm{N}, 4.10 \%$.

Binitroxide (15b). A yellow waxy solid. Yield: $21 \mathrm{mg}(20 \%)$. There are no peaks in the DSC curve on the heating run. IR (solid, $\mathrm{KBr}, v_{\max }, \mathrm{cm}^{-1}$ ): 1762, $1733(\mathrm{C}=\mathrm{O}), 1585,1558(\mathrm{C}=\mathrm{N})$. ESR: $\mathrm{t}, \mathrm{A}_{\mathrm{N}} 1.45 \mathrm{mT}, g_{\text {iso }}$ 2.0058. Anal. calcd for $\mathrm{C}_{133} \mathrm{H}_{200} \mathrm{ClN}_{7} \mathrm{O}_{14}$ (2156.50): C, 74.07; H, 9.35; N, 4.55; Cl 1.64. Found: C, 74.20; H, 9.45; N, 4.53; $\mathrm{Cl} 1.63 \%$. 
Binitroxide (2b). A mixture of $112 \mathrm{mg}(0.11 \mathrm{mmol})$ of4-[(5r,8r)-3-(4-hydroxyphenyl)-2,2-dimethyl-1-oxido-1,4diazaspiro[4.5]dec-1-en-8-yl]phenyl 3,4,5-tris(dodecyloxy)benzoate (trans-4), $9 \mathrm{mg}$ (0.05 mmol) of 2,4dichloro-6-methoxy-1,3,5-triazine, and $15 \mathrm{mg}(0.11 \mathrm{mmol})$ of potassium carbonate in $2 \mathrm{~mL}$ of dry acetone was refluxed for $5 \mathrm{~h}$. The solvent was evaporated, and the residue was mixed with water $(4 \mathrm{~mL})$ and chloroform (10 $\mathrm{mL}$ ). The organic layer was separated, washed with water, and dried over $\mathrm{MgSO}_{4}$. The filtrate was condensed in vacuum, and the residue was mixed with $5 \mathrm{~mL}$ of EtOH and cooled to $0{ }^{\circ} \mathrm{C}$. The formed precipitate was immediately filtered off, washed with $\mathrm{EtOH}$, and air dried to obtain $\mathbf{2 b}$ as a yellow waxy solid (31 mg, $45 \%)$. There are no peaks in the DSC curve on the heating run. IR (solid, $\mathrm{KBr}, v_{\max }, \mathrm{cm}^{-1}$ ): 1762, 1732 (C=O), 1581, 1560 (C=N). ESR: $t, A_{N} 1.45$ mT, $g_{\text {iso }}$ 2.0058. Anal. calcd for $\mathrm{C}_{134} \mathrm{H}_{203} \mathrm{~N}_{7} \mathrm{O}_{15}$ (2152.08): $\mathrm{C}, 74.78 ; \mathrm{H}, 9.51 ; \mathrm{N}, 4.56$. Found: $\mathrm{C}, 74.30 ; \mathrm{H}, 9.45 ; \mathrm{N}, 4.53 \%$.

Trinitroxide (1c) and binitroxide (15c) were obtained analogously to compounds $\mathbf{1 b}$ and $\mathbf{1 5 b}$ from compound cis-5.

Trinitroxide (1c). A yellow waxy solid (61 mg, 42\%). There are no peaks in the DSC curve on the heating run. IR (solid, $\mathrm{KBr}, v_{\max } \mathrm{cm}^{-1}$ ): $1703(\mathrm{C}=\mathrm{O}), 1585,1546(\mathrm{C}=\mathrm{N})$. ESR: $\mathrm{t}, \mathrm{A}_{\mathrm{N}} 1.45 \mathrm{mT}, g_{\text {iso }}$ 2.0058. Anal. calcd for $\mathrm{C}_{180} \mathrm{H}_{288} \mathrm{~N}_{9} \mathrm{O}_{21}$ (2914.26): C, 74.18; $\mathrm{H}, 9.96 ; \mathrm{N}, 4.33$. Found: $\mathrm{C}, 74.24 ; \mathrm{H}, 9.97 ; \mathrm{N}, 4.40 \%$.

Binitroxide (15c). A yellow waxy solid (20 mg, 20\%). There are no peaks in the DSC curve on the heating run. IR (solid, $\mathrm{KBr}, v_{\max }, \mathrm{cm}^{-1}$ ): $1712(\mathrm{C}=\mathrm{O}), 1604,1568(\mathrm{C}=\mathrm{N})$. ESR: $\mathrm{t}, \mathrm{A}_{\mathrm{N}} 1.45 \mathrm{mT}, g_{\text {iso }}$ 2.0058. Anal. calcd for $\mathrm{C}_{121} \mathrm{H}_{192} \mathrm{ClN}_{7} \mathrm{O}_{14}$ (2004.31): C, 72.51; $\mathrm{H}, 9.66 ; \mathrm{N}, 4.89 ; \mathrm{Cl}, 1.77$. Found: $\mathrm{C}, 72.86 ; \mathrm{H}, 9.60 ; \mathrm{N}, 4.82 ; \mathrm{Cl}, 1.76 \%$.

Binitroxide (2c) was prepared similarly to compound $\mathbf{2 b}$ from cis-5. A yellow waxy solid (46 mg, 46\%); $\mathrm{mp} 72-$ $74^{\circ} \mathrm{C}$. IR (solid, $\mathrm{KBr}, v_{\max }, \mathrm{cm}^{-1}$ ): $1708(\mathrm{C}=0)$ ) 1585, $1560(\mathrm{C}=\mathrm{N})$. ESR: $\mathrm{t}, \mathrm{A}_{\mathrm{N}} 1.45 \mathrm{mT}, g_{\text {iso }} 2.0058$. Anal. calcd for $\mathrm{C}_{122} \mathrm{H}_{195} \mathrm{~N}_{7} \mathrm{O}_{15}$ (1999.89): C, 73.27; $\mathrm{H}, 9.83 ; \mathrm{N}, 4.90$. Found: $\mathrm{C}, 73.01 ; \mathrm{H}, 9.60 ; \mathrm{N}, 4.85 \%$.

\section{X-Ray crystallography}

The X-ray single-crystal diffraction data for triradical 1a were collected at $200 \mathrm{~K}$ on a Bruker Kappa APEX II instrument with MoK $\alpha$ radiation $(\lambda=0.71073 \AA)$ and a CCD area detector. The structures were solved by direct methods in the SHELXS software and refined on $F^{2}$ using all the data by full-matrix least-square procedures in SHELXL-97. Multiscan absorption corrections were performed in the SADABS software. The positions of nonhydrogen atoms were refined with anisotropic displacement parameters. All hydrogen atoms were included in the calculated positions with isotropic displacement parameters at 1.2 times the isotropic equivalent of their carrier atoms. The guest molecules of hexane and EtOAc are strongly disordered and located next to the threefold and rotoinversion threefold axes. Therefore, the SQUEEZE function in PLATON was employed to calculate the potential solvent-accessible area in the unit cell; $3 \times 396$ and $3 \times 140 \AA^{3}$ were calculated containing approximately $3 \times 106$ and $3 \times 37$ electrons. Accordingly, the first three voids may contain six solvent molecules (hexane/EtOAc), and the next three voids may contain water or be empty.

Crystal data on 1a (without guest solvents): $\mathrm{C}_{51} \mathrm{H}_{60} \mathrm{~N}_{9} \mathrm{O}_{6}, \mathrm{FW} 895.08$, rhombohedral, space group R-3, $a=$ $b=20.6189(6), c=22.8065(8) \AA, \alpha=6=90, v=120^{\circ}, \mathrm{V}=8396.9(5) \AA^{3}, \mathrm{Z}=6, \mu(\mathrm{MoK} \alpha)=0.071 \mathrm{~mm}^{-1}, \rho_{\text {calc }}=$ $1.062 \mathrm{~g} \cdot \mathrm{cm}^{-3}, 2 \vartheta_{\max }=52^{\circ}, \mathrm{GOF}=1.09, \mathrm{wR}\left(F^{2}\right)=0.2217$ (all 3675 data), $\mathrm{R}=0.0607$ [2866 data with $\mathrm{I}>2 \sigma(\mathrm{I})$ ], CCDC 1578986.

\section{Acknowledgements}

This work was supported by the Russian Foundation for Basic Research (grant \# 17-53-50043). 


\section{Supplementary Material}

$\mathrm{IR},{ }^{1} \mathrm{H}$ and ${ }^{13} \mathrm{C}$ NMR spectra and phase transition data of new compounds.

\section{References}

1. Wolff, J. J.; Siegler, F.; Matschiner, R.; Wortmann, R. Angew. Chem. Int. Ed. 2000, 39, 1436. http://dx.doi.org//10.1002/(SICI)1521-3773(20000417)39:8<1436::AID-ANIE1436>3.0.CO;2-U

2. Cherioux, F.; Maillotte, H.; Audebert, P.; Zyss, J. Chem. Commun. 1999, 2083. http://dx.doi.org//10.1039/A905899K

3. Wöhrle, T.; Wurzbach, I.; Kirres, J.; Kostidou, A.; Kapernaum, N.; Litterscheidt, J.; Haenle, J. C.; Staffeld, P.; Baro, A.; Giesselmann, F.; Laschat, S. Chem. Rev. 2016, 116, 1139.

http://dx.doi.org//10.1021/acs.chemrev.5b00190

4. Yang, F.; Xie, J.; Guoa, H.; Xua, B.; Lia, C. Liq. Cryst. 2012, 39, 1368. http://dx.doi.org//10.1080/02678292.2012.717112

5. Majumdara, K. C.; De, N.; Roy, B.; Bhaumik, A. Liq. Cryst. 2010, 37, 1459. http://dx.doi.org//10.1080/02678292.2010.520750

6. Goldmann, D.; Janietz, D.; Festag, R.; Schmidt, C.; Wendorff, J. H. Liq. Cryst. 1996, $21,619$. http://dx.doi.org//10.1080/02678299608032873

7. Holst, H. G.; Pakulab, T.; Meier, H. Tetrahedron 2004, 60, 6765. http://dx.doi.org//10.1016/j.tet.2004.06.031

8. Lee, C.; Yamamoto, T. Tetrahedron Lett. 2001, 42, 3993. http://dx.doi.org//10.1016/S0040-4039(01)00640-2

9. Veerabhadraswamy, B. N.; Dambal, H. K.; ShankarRao, D. S.; Yelamaggad, C. V. Chem PhysChem 2016, 17, 2225.

http://dx.doi.org//10.1002/cphc.201600280

10. Laventure, A.; De Grandpre, G.; Soldera, A.; Lebel, O.; Pellerin, C. Phys. Chem. Chem. Phys. 2016, $18,1681$. http://dx.doi.org//10.1039/c5cp06630a

11. El-Faham, A.; Dahlous, K.; AL Othman, Z. A.; Al-Lohedan, H. A.; El-Mahdy, G. A. Molecules 2016, $21,436$. http://dx.doi.org//10.3390/molecules21040436

12. Stegbauer, L.; Schwinghammer, K.; Lotsch, B. V. Chem. Sci. 2014, 5, 2789. http://dx.doi.org//10.1039/c4sc00016a

13. Tamura, R.; Uchida, Y.; Suzuki, K. In Handbook of Liquid Crystals (2 ${ }^{\text {nd }}$ Ed.); Goodby, J. W.; Collings, P. J.; Kato, T.; Tschierske, C.; Gleeson, H. F.; Raynes, P. Eds.; Wiley-VCH: Weinheim, 2014; Vol. 8, pp. 837-864.

14. Tamura, R.; Uchida, Y.; Ikuma, N. J. Mater. Chem. 2008, 18, 2872. http://dx.doi.org//10.1039/B802407C

15. Suzuki, K.; Takemoto, Y.; Takaoka, S.; Taguchi, K.; Uchida, Y.; Mazhukin, D. G.; Grigor`ev, I. A.; Tamura, R. Chem. Commun. 2016, 52, 3935. http://dx.doi.org//10.1039/c5cc09202g

16. Castellanos, S.; Lopez-Calahorra, F.; Brillas, E.; Julia, L.; Velasco, D. Angew. Chem. Int. Ed. 2009, 48, 6516. http://dx.doi.org//10.1002/anie.200902641

17. Jankowiak, A.; Pociecha, D; Monobe, H.; Szczytko, J.; Kaszynski, P. Chem. Commun. 2012, 48, 7064. http://dx.doi.org//10.1039/c2cc33051b 
18. Jankowiak, A.; Pociecha, D; Szczytko, J.; Monobe, H.; Kaszynski, P. J. Am. Chem. Soc. 2012, 134, 2465. http://dx.doi.org//10.1021/ja209467h

19. Jasinski, M.; Pociecha, D.; Monobe, H.; Szczytko, J.; Kaszynski, P. J. Am. Chem. Soc. 2014, 136, 14658. http://dx.doi.org//10.1021/ja507594h

20. Jasinski, M.; Szczytko, J.; Pociecha, D.; Monobe, H.; Kaszynski, P. J. Am. Chem. Soc. 2016, $138,9421$. http://dx.doi.org//10.1021/jacs.6b06444

21. Uchida, Y.; Suzuki, K.; Tamura, R.; Ikuma, N.; Shimono, S.; Noda, Y.; Yamauchi, J. J. Am. Chem. Soc. 2010, $132,9746$.

http://dx.doi.org//10.1021/ja101930d

22. Suzuki, K.; Uchida, Y.; Tamura, R.; Shimono, S.; Yamauchi, J. J. Mater. Chem. 2012, 22, 6799. http://dx.doi.org//10.1039/c2jm16278d

23. Ravat, P.; Marszalek, T.; Pisula, W.; Müllen, K.; Baumgarten. M. J. Am. Chem. Soc. 2014, 136, 12860. http://dx.doi.org//10.1021/ja507421x

24. Suzuki, K.; Uchida, Y.; Tamura, R.; Noda, Y.; Ikuma, N.; Shimono, S.; Yamauchi, J. Soft Matter 2013, 9, 4687. http://dx.doi.org//10.1039/C3SM27295H

25. Rozenberg, A. N.; Povoroznik, O. M.; Golubev, V. A.; Sen, V. D.; Bogdanov, G. N. Izv. Akad. NaukSSSR, Ser. Khim. 1977, 875; Chem. Abstr. 1977, 87, 68294a.

26. Chalmers, A. M.; Jack, J.; Cook, B. U.S. Pat. 4028 334, 1977; Chem. Abstr. 1977, 87, P $202584 a$.

27. Sommerlade, R.; Grutzmacher, H.; Boulmaaz, S. Eur. Pat. Appl. 1103537, 2001; Chem. Abstr. 2001, 135, P $5246 a$.

28. Li, J.; Zhang, Z.; Zhu, X.; Zhu, J.; Cheng, Z. e-Polymers 2010, 10, no. 145. http://dx.doi.org//10.1515/epoly.2010.10.1.1622

29. Peng, L.; Chen, C.; Gonzalez, C. R.; Balogh-Nair, V. Int. J. Mol. Sci. 2002, 3, 1145. http://dx.doi.org//10.3390/i3111145

30. Wang, H.; Wang, J.; Yang, Q.; Zhang, X.; Gao, P.; Xu, S.; Sun, X.-L.; Wang, Y. K. Neurochem. Res. 2015, 40, 1526. http://dx.doi.org//10.1007/s11064-015-1602-5

31. Nesvadba, P.; Bugnon, L. PCT Int. Appl. 107468, 2007; Chem. Abstr. 2007, 147, P 409765a.

32. Lahti, P. M.; Liao, Y.; Julier, M.; Palacio, F. Synth. Met. 2001, 122, 485. http://dx.doi.org//10.1016/S0379-6779(01)00340-X

33. Hayami, S.; Inoue, K. Chem. Lett.1999, 28, 545. http://dx.doi.org//10.1246/cl.1999.545

34. Zaytseva, E. V.; Gatilov, Yu. V.; Amitina, S. A.; Tamura, R.; Grigor'ev, I. A.; Mazhukin, D. G. Russ. J. Org. Chem. (Engl. Transl.) 2014, 50, 72. http://dx.doi.org//10.1134/S107042801401014X

35. Zaitseva, E. V.; Shernyukov, A. V.; Amitina, S. A.; Tamura, R.; Grigor`ev, I. A.; Mazhukin, D. G. Chem. Heterocycl. Compd. (Engl. Transl.) 2014, 50, 1113. http://dx.doi.org//10.1007/s10593-014-1571-7

36. Zaytseva, E. V.; Shernyukov, A. V.; Genaev, A. M.; Tamura, R.; Grigor'ev, I. A.; Mazhukin D. G. Arkivoc 2014, (vi), 10. http://dx.doi.org//10.3998/ark.5550190.p008.808

37. Swamy, K. C. K.; Kumar, N. N. B.; Balaraman, E.; Kumar, K. V. P. P. Chem. Rev. 2009, 109, 2551. http://dx.doi.org//10.1021/cr800278z

38. Aakeroy, C. B.; Desper, J.; Urbina, J. F. Cryst. Eng. Comm. 2005, 7, 193. http://dx.doi.org//10.1039/b419029g 
39. Saraswatula, V. G.; Bhat, M. A.; Bhattacharya, S.; Saha B. K. J. Chem. Sci. 2014, 126, 1265. http://dx.doi.org//10.1007/s12039-014-0690-0

40. Hersmis, M. C.; Spiering, A. J. H.; Waterval, R. J. M.; Meuldijk, J.; Vekemans, J. A. J. M.; Hulshof L. A. Org. Process. Res. Dev. 2001, 5, 54.

http://dx.doi.org//10.1021/op000066e

41. Naseer, M. M.; Wang, D. X.; Zhao, L.; Huang, Z. T., Wang, M. X. J. Org. Chem. 2011, 76, 1804. http://dx.doi.org//10.1021/jo102483x 